\title{
EVALUATION OF SUCCESS OF SINGLE DRILLING IMPLANT SYSTEM (CLINICAL AND RADIOGRAPHIC STUDY)
}

\author{
Emad A. Senada ${ }^{* B B S}$, Samraa A. El Sheikh ${ }^{2 h D}$, Mervat M. Khalil ${ }^{2 p h D}$.
}

\begin{abstract}
INTRODUCTION: Preparation of the implant osteotomy has been classically performed using drills of various shapes to conform the site to the implant's geometry. Drilling procedures may cause not only mechanical trauma to the bone but also heat-induced bone necrosis, thus representing a significant risk for failed osseointegration. As an alternative single drilling osteotomy is a technique that allows effective bone cutting with minimally traumatic procedures and less heat generation.

OBJECTIVES: Evaluation of single drilling implant site preparation in affecting implant stability and crestal bone loss that takes place around the implant.

MATERIALS AND METHODS: The study was conducted on thirteen patients having missing posterior mandibular teeth indicated for implant restoration. All implants were placed using single drilling osteotomy. After 3 months, final crowns were delivered. All implants were followed for 6 months. Clinically, each patient was evaluated for pain, swelling and stability of the implant. Radiographically, cone beam computed tomography (CBCT) was used for the assessment of marginal bone level and bone density.

RESULTS: There was a significant increase in bone density from immediate postoperative to the end of the 6 months. The mean of marginal bone level from immediately post-operative to the 3rd month was significant and from immediate to 6th month was significant. One case displayed swelling in the first week and the implant was removed (failure case) due to lack of oral hygiene maintenance by the patient.

CONCLUSIONS: Single drilling osteotomy was a successful treatment procedure, with satisfactory clinical outcomes, and a low incidence of complications.

KEY WORDS: Dental implant, implant site preparation, surgical drills, single drilling implant. RUNNING TITLE: Implants single drilling osteotomy technique.

1 BDS,2010, Faculty of Dentistry, Alexandria University, Egypt.

2 Professor of Oral and Maxillofacial Surgery, Department of Oral and Maxillofacial Surgery Faculty of Dentistry, Alexandria University, Egypt.
\end{abstract}

* Corresponding author

E-mail: dremadadel2014@gmail.com

\section{INTRODUCTION}

The success of dental implants depends on the concept of osseointegration introduced by Branemark which implies the structural and functional contact between the implant and the surrounding vital bone (1). According to Alberktsson et al. (2) The six most important factors for establishing a reliable osseointegration are implant material, implant design, surface quality, bone status, surgical technique and loading conditions.

Primary stability is a critical factor that determines the longterm success of dental implants. It is responsible for preventing the micro motion of the implant in the bone site, promoting natural healing and effective bone formation until adequate biological stability has been established. Primary stability of dental implants is highly dependent on implant design, surgical technique and the bone density and quality (3). The thermal and mechanical damage produced by the drilling procedures has been associated with a combination of variables: drill speed, drill diameter, drill geometry, irrigation and drilling pressure. (4-8). Therefore, any simplification of the techniques for site preparation can be favorably accepted by both clinicians and patients. Some improvements of the drill design and drilling technique have been proposed in order to reduce the risk of overheating the implant site and simplify the procedure $(9,10)$. Moreover, a minimally traumatic procedure is recommended for preserving the healing potential of bone as much as possible and to reduce crestal bone loss as well (11).

Recently, new hollow drill in a single drilling system was developed. It was hypothesized that hollow drill design with single drilling system results in decreasing time for surgery (faster implant placement) and minimum bone removal for implant site preparation and so reduces bone trauma and micro-fractures and fasters healing time. Moreover, the hollow design allows harvesting of bone core that bone can be used in bone grafting materials as self-bone grafting. (12) The present study therefore aimed to evaluate clinical performance of a recently developed hollow drill in a single drilling system for replacement of mandibular posterior teeth.

\section{MATERIALS AND METHODS Study design}

This study was conducted on thirteen patients with age ranging from 20 to 40 years with a mean age of $(29.46$ \pm 5.81 ) years; they were females with missing mandibular premolar teeth indicated for implant placement using two stage surgery. Patients were selected from the Outpatient Clinic of the Oral and Maxillofacial Surgery Department Faculty of Dentistry, Alexandria University. 
Inclusion criteria:

- Patients with missing mandibular posterior teeth with adequate bone quality and inter-occlusal space.

- Patients should have adequate oral hygiene and periodontal condition.

\section{Exclusion criteria:}

- The patient should be free from any relevant systemic disease that is contraindicated for implant surgery or may affect bone healing.

- Patients with parafunctional habits.

- Heavy smoking patients (more than 10 cigarettes per day) and alcoholism.

\section{Informed consent}

All patients received thorough explanations about the planned treatment and its potential risks and complications, and signed a written informed consent prior to being enrolled in the study. It was also mentioned that the patient had the right of withdrawal from the study anytime without any consequences. Ethical approval for this study was obtained from the research ethics committee, Faculty of Dentistry, Alexandria University before beginning the study.

\section{Materials}

\section{Implant system}

All implants IBS (InnoBioSurg Co.,Ltd, Korea ) were made of titanium alloy with SLA (Sandblasted with Large grit and Acid etched) surface.

Implants were available in different sizes, lengths (7 - 9 - 11$13 \mathrm{~mm})$ and diameters (4 - $4.5-5 \mathrm{~mm})$. These implants had the following features; a switched platform, a tapered shape, a conical connection with hex base and single threads with new design "fin threads". They were specially designed for self-tapping which cuts through the bone with no bone chipping while simultaneously condensing the bone, in order to optimize the achievement of primary stability in any type of bone density. (Figure 1)

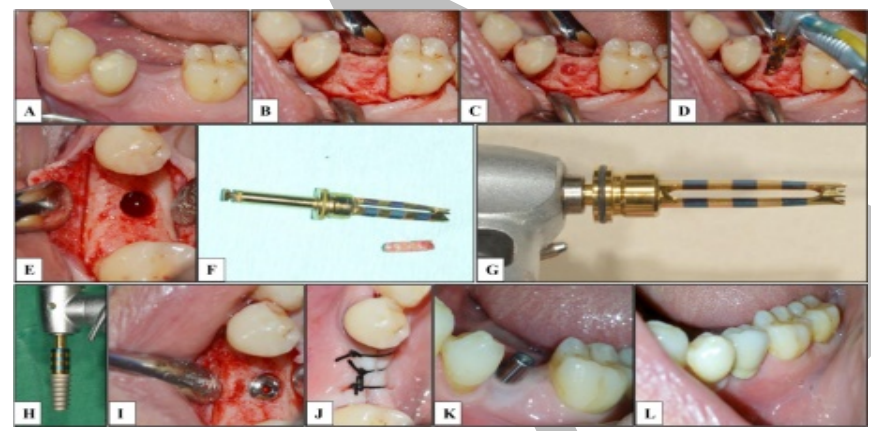

Figure 1: A: Clinical overview. B: Mucoperiosteal flap. C: Magic Marking Drill. D: Drilling the bone. E: Osteotomy site. F: The bone core. G: The shape of the drill. H: the implant shape. I: Cover screw, J: Suturing. K: Abutment in place. L: Final porcelain restoration 3 months postoperative.

The surgical kit of IBS dental implant (IBS: InnoBioSurg Co., Ltd, Korea).

Drills (Figure1 F, G, H)

- Magic marking drill

- Used to mark the location for fixture to be placed

- Magic drills

- With different diameter (4, 4.5, 5, $5.5 \mathrm{~mm}$ ) and lengths (7, 9, 11, $13 \mathrm{~mm})$, hollow drill for osteotomy.

- Magic depth drill

- Has a forward-moving blade only

- Used to secure accurate depth after removing bone core

- Used to determine bone quality of the placement hole floor

\section{Others}

- Drill stopper, Hex driver, Machine driver, Mount driver, Torque Ratchet

Osstell ISQ (Osstell ISQ, Osstell AB, stampgatan 14, SE 41101 Goteborg, Sweden.)

It is an implant stability meter that uses resonance frequency analysis as a method of measurement. It consists of:

- Osstell ISQ instrument.

- Probe.

- Charger.

- USB cable.

- Test peg.

Methods

\section{A) Pre-surgical phase}

Prior to implant placement, each patient was investigated clinically and radiographically. All patients were subjected to a detailed history taking including: personal data, medical history and dental history. Clinical evaluation of the implant site including inspection, palpation of the edentulous alveolar ridge, the occlusion, and inter-occlusal space. Primary alginate impressions for both arches were taken and diagnostic study models were prepared. Study casts were used to evaluate the jaw relationship and the inter-occlusal space. Pre-operative Cone Beam Computed Tomography (CBCT) was done for all patients to detect any clinically undetectable pathology, important anatomical structures, Bone width, implant position, angulation and depth.

\section{B) Surgical phase}

Chlorohexidine gluconate $0.12 \%$ mouth wash (Hexitol mouthwash, Arab drug company, Cairo, Egypt) was used to rinse for 30 seconds before operation. All patients were operated under local anaesthesia. Crestal incision was performed and full thickness mucoperiosteal flap was reflected to access the site. The implant bed was prepared using the new specially-designed drill. These drills are available with four drilling lengths $(7,9,11,13 \mathrm{~mm})$ characterized by different color codes, and three different diameters $(4,4.5,5 \mathrm{~mm})$. They allow a single drilling procedure before implant placement in bone with all types. Drilling speed of 1500 RPM and profuse normal saline irrigation were used throughout the drilling procedure. Tapered implants with an internal connection and SLA treated surface were inserted in all patients with insertion torque $30-50 \mathrm{Ncm}$. The SmartPeg was attached to the dental implant for measuring primary stability using Osstell. A cover screw supplied with the implant was inserted on the implant with the use of implant screw driver. Suturing of the flap with interrupted sutures, using $3 / 0$ black silk suturing material. (Figure 1)

\section{C) Postsurgical phase}

1- Postoperative instructions including: cold fomentations to the surgical site extraorally for the same day of operation in an intermittent manner every ten minutes for at least 3 hours to minimize postoperative edema and swelling and maintain daily routine oral hygiene after surgery and Patients were instructed to eat a soft diet for 7 days.

2- All patients received postoperative medications including

- Broad-spectrum oral antibiotics: Amoxicillin $875 \mathrm{mg} /$ Clavulanic acid 125mg (Augmentin 1gm Tablets, Medical 
Union Pharmaceuticals (MUP), GlaxoSmithKline, Cairo, Egypt) in a dose of one capsule twice daily for a week

- Non-steroidal anti-inflammatory drugs Ibuprofen $400 \mathrm{mg}$ (Brufen tablet 400mg Abbott, Cairo, Egypt) at a dose of one tablet three times daily for four days.

Chlorhexidine 0.12\% mouthrinses (Hexitol mouth wash, Arab Drug Co. (ADCO) were prescribed for 2 weeks to enhance plaque control.

\section{3- Post-operative evaluation}

\section{I- Clinical evaluation}

- Patients were evaluated clinically at interval of one and two weeks postoperatively for presence of pain using the Visual Analogue scale (VAS) (13), Presence of Swelling or infection and implant stability. The implant stability measurement was examined immediately at the time of implant insertion and at 3 months postoperatively using the Resonance Frequency Analysis via the Osstell ISQ system (Osstell ${ }^{\circledR}$, integration Diagnostics AB, Goteborg, Sweden.).

\section{II- Radiographic evaluation:}

- Cone beam computed tomography (CBCT) (i-CAT Next Generation, Imaging Sciences International, Hatfield, PA, USA) was obtained pre-operatively, 3 months and 6 months postoperatively to assess:

\section{Bone density around the implant}

- Image reconstruction was performed using a special software called "Ondemand 3D" (Ondemand 3D: Cybermed, Korea) version 1.0.7. Measurements were taken as follows:

- The bone density apical, buccal and lingual to the implant was used as a known measurement in Hounsfield Unit (HU).

- Mean, standard deviation, minimum and maximum readings were automatically displayed by the system.

\section{Marginal bone level}

- Marginal bone level was measured from the crest of the implant to the apical level of the implant. This was done buccally and lingually. Height was recorded in millimeters.

- The mean of the buccal and lingual bone heights was calculated for each implant. (Figure 2)

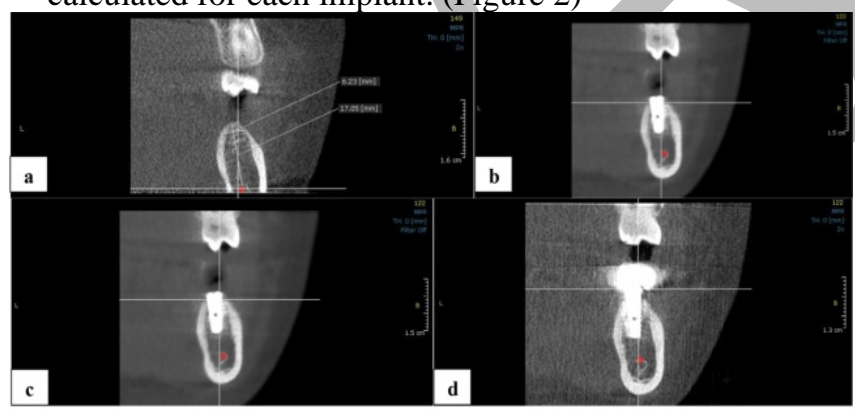

Figure 2: Radiographic follow up of case. A: Preoperative CBCT of implant site. B: Immediate CBCT of implant site postoperatively. C: Third month CBCT of the implant site postoperatively. D: Sixth month CBCT of the implant site postoperatively.

\section{D) Prosthetic phase}

After 3 months, the cover screw was removed and the healing abutment was tightened.
After 1-2 weeks, the healing abutment was removed and the abutment was tightened with insertion torque $35 \mathrm{Ncm}$, and definitive porcelain fused to metal restoration was delivered to all patients

\section{Statistical analysis}

Data were fed to the computer and analyzed using IBM SPSS software package version 20.0 (14) (Armonk, NY: IBM Corp). Quantitative data were described using range, mean, standard deviation and median. The distribution of quantitative variables was tested for normality using Kolmogorov-Smirnov test. The paired t- test was used to compare between two periods showing normally distributed quantitative variables, while the ANOVA with repeated measures was used to compare between more than two periods or stages, and Bonferroni Post Hoc test. The Friedman test was used for abnormally distributed quantitative variables, with Dunn's Post Hoc Test. Significance of the obtained results was judged at the $5 \%$ level.

\section{RESULTS}

Thirteen patients with extracted mandibular posterior teeth indicated for implant placement were evaluated in this study. Their ages ranged from 20 to 40 years. Thirteen implants were placed; $4 \mathrm{~mm}$ diameter $\times 9 \mathrm{~mm}$ length were placed in three patients, $4.5 \mathrm{~mm}$ diameter $\times 11 \mathrm{~mm}$ length were placed in two patients, $4.5 \mathrm{~mm}$ diameter $\times 13 \mathrm{~mm}$ length were placed in one patient, $4 \mathrm{~mm}$ diameter $\times 11 \mathrm{~mm}$ length were placed in three patients, $5 \mathrm{~mm}$ diameter $\times 13 \mathrm{~mm}$ length were placed in two patients, $5 \mathrm{~mm}$ diameter $\times 9 \mathrm{~mm}$ length were placed in one patient and $5.5 \mathrm{~mm}$ diameter $\times 11 \mathrm{~mm}$ length were placed in one patient.

All patients were followed up for six months and the results were registered as regards: clinical evaluation and radiographic evaluation.

\section{I- Clinical evaluation}

1. Presence of pain: Pain was evaluated daily for two weeks using visual analogue scale (VAS) (13) from 0 to 10 ("0" is pain free and "10" is unbearable pain). After surgery, five patients experienced mild pain (VAS=2-4), three patients experienced moderate pain (VAS=5-7), one patient experienced severe pain and four patients experienced no pain at surgical site for 1-3 days duration.

During the follow up period, all patients felt no pain after implant placement except one case that felt severe postoperative pain in the first week after implant placement.

2. Presence of Swelling: In only one case, swelling in the operated area was found in the first week of implant placement (failure case). In the other cases, patients continued the follow up period without clinical signs of inflammation, peri-implant infections after implant placement or during the evaluation period.

3. Implant stability quotient (ISQ) was measured by Osstell (Table 1, Figure 3). The mean implant stability quotient at day of surgery was $72.29 \pm 5.07$. There was an increase in $3^{\text {rd }}$ month post-operatively $76.67 \pm 6.75$. The increase in implant stability quotient in three months was statistically significant.

Table (1): Comparison between the three periods according to Osstell. 


\begin{tabular}{|c|c|c|c|c|c|}
\hline Osestell & $\begin{array}{c}\text { Baseline } \\
(n=13)\end{array}$ & $\begin{array}{c}3^{\text {rd }} \\
\text { month } \\
(n=12)\end{array}$ & $\begin{array}{c}\mathbf{6}^{\text {th }} \\
\text { month } \\
(\mathrm{n}=12)\end{array}$ & $\mathbf{F}$ & $\mathbf{p}$ \\
\hline $\begin{array}{l}\text { Min. - } \\
\text { Max. }\end{array}$ & $55.0-83.0$ & & $63.0-82.0$ & & \\
\hline $\begin{array}{l}\text { Mean } \pm \\
\text { SD. }\end{array}$ & $72.15 \pm 9.33$ & $73.85 \pm 5.26$ & $76.46 \pm 5.90$ & $8.155^{*}$ & $0.011^{*}$ \\
\hline Median & 75.0 & 76.0 & 79.0 & & \\
\hline $\begin{array}{c}\text { Sig. bet. } \\
\text { periods }\end{array}$ & \multicolumn{3}{|c|}{$\mathrm{p}_{1}=0.707, \mathrm{p}_{2}=0.011^{*}, \mathrm{p}_{3}<0.001^{*}$} & & \\
\hline
\end{tabular}

F: F test (ANOVA) with repeated measures, Pairwise comparison bet. each 2 groups was done using Post Hoc Test (Bonferroni)

p: $p$ values for comparing between three periods

p1: p values for comparing between Immediate and $3^{\text {rd }}$ month

p2: p values for comparing between Immediate and $\mathbf{6}^{\text {th }}$ month

$\mathbf{p}_{3}$ : p values for comparing between $3^{\text {rd }}$ month and $\mathbf{6}^{\text {th }}$ month

*: Statistically significant at $\mathrm{p} \leq 0.05$

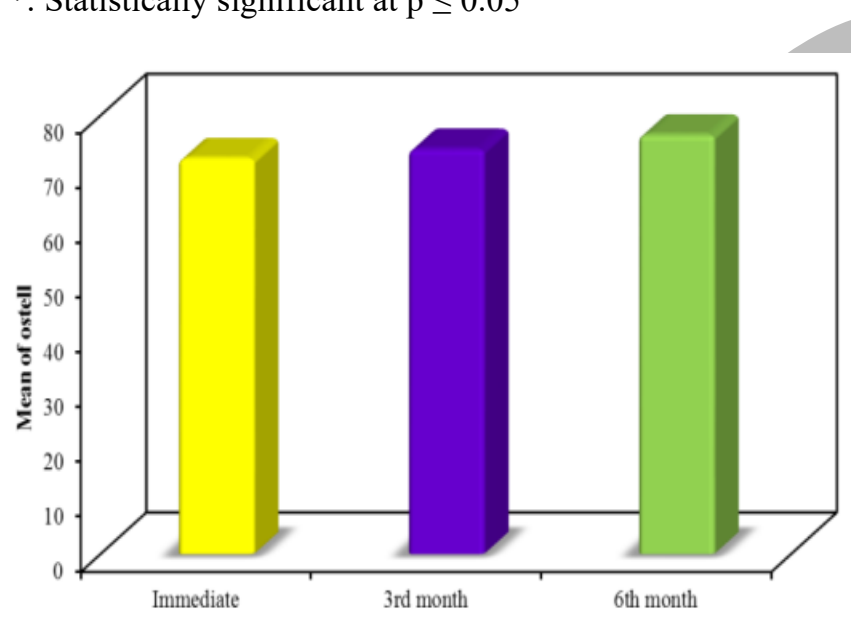

Figure 3: Comparison between the three periods according to Osstell.

One implant was removed in the first week that was regarded as a failure case.

\section{II- Radiographic Evaluation:}

\section{Bone density}

Data were collected regarding mean peri-implant bone density values, standard deviation and percentage of change at immediate, 3 months and 6 months. (Table 2, Figure 4)

In the immediate post-operative phase, the mean periimplant bone density was $606.8 \pm 216.8 \mathrm{HU}$ with a minimum recorded value of $230.5 \mathrm{HU}$ and a maximum recorded value of $977.2 \mathrm{HU}$.

In the third month, the mean peri-implant bone density was $933.9 \pm 194.7 \mathrm{HU}$ with a minimum recorded value of 562.6 $\mathrm{HU}$ and a maximum recorded value of $1235.2 \mathrm{HU}$.

In the sixth month, the mean peri-implant bone density was $994.4 \pm 131.8 \mathrm{HU}$ with a minimum recorded value of 806.5 $\mathrm{HU}$ and a maximum recorded value of $1236.9 \mathrm{HU}$. These differences were statistically significant $(\mathrm{p}<0.05)$.

\section{Marginal bone level}

Alexandria Dental Journal. Volume 45 Issue 2
Data were collected regarding the marginal bone level at the mesial and distal aspects of all implants at immediate, 3 months and 6 months.

The data collected was tabulated and the statistical analysis of the marginal bone level scores was done for all patients. (Table 3, Figure 5)

In the immediate postoperative phase, the mean marginal bone level (MBL) value was $9.60 \pm 1.06 \mathrm{~mm}$ with a minimum-recorded value of $8.60 \mathrm{~mm}$ and a maximumrecorded value of $11.56 \mathrm{~mm}$.

In the third month, the mean MBL value was $9.09 \pm 1.09 \mathrm{~mm}$ with a minimum-recorded value of $8.19 \mathrm{~mm}$ and a maximum-recorded value of $11.12 \mathrm{~mm}$.

In the sixth month, the mean MBL value was $8.71 \pm 1.05 \mathrm{~mm}$ with a minimum-recorded value of $7.74 \mathrm{~mm}$ and a maximum-recorded value of $10.67 \mathrm{~mm}$. These differences were statistically significant ( $\mathrm{p}<0.05)$.

Table (2): Comparison between the three periods according to bone density.

\begin{tabular}{|l|l|c|c|c|c||}
\hline $\begin{array}{l}\text { Bone } \\
\text { density }\end{array}$ & $\begin{array}{l}\text { Baseline } \\
(\mathbf{n = 1 3})\end{array}$ & $\begin{array}{c}3^{\text {rd }} \text { month } \\
(\mathbf{n = 1 2})\end{array}$ & $\begin{array}{c}\mathbf{6}^{\text {th }} \text { month } \\
(\mathbf{n = 1 2})\end{array}$ & $\mathbf{F}$ & $\mathbf{p}$ \\
\hline $\begin{array}{l}\text { Min. }- \\
\text { Max. }\end{array}$ & $230.5-977.2$ & $562.6-1235.2$ & $806.5-1236.9$ & & \\
$\begin{array}{l}\text { Mean } \pm \\
\text { SD. } \\
\text { Median }\end{array}$ & $606.8 \pm 216.8$ & $933.9 \pm 194.7$ & $994.4 \pm 131.8$ & $36.566^{*}$ & $<0.001$ \\
\hline $\begin{array}{l}\text { Sig. bet. } \\
\text { periods }\end{array}$ & \multicolumn{2}{|c|}{$\mathrm{p}_{1}<0.001^{*}, \mathrm{p}_{2}<0.001^{*}, \mathrm{p}_{3}=0.184$} & & \\
\hline
\end{tabular}

F: $F$ test (ANOVA) with repeated measures, Pairwise comparison bet. each 2 groups was done using Post Hoc Test (Bonferroni)

p: $\mathrm{p}$ values for comparing between three periods

$\mathbf{p}_{1}$ : $\mathrm{p}$ values for comparing between Immediate and $3^{\text {rd }}$ month

$\mathbf{p}_{2}$ : $\mathrm{p}$ values for comparing between Immediate and $\mathbf{6}^{\text {th }}$ month

$\mathbf{p}_{3}$ : $\mathrm{p}$ values for comparing between $3^{\text {rd }}$ month and $6^{\text {th }}$ month *: Statistically significant at $\mathrm{p} \leq 0.05$

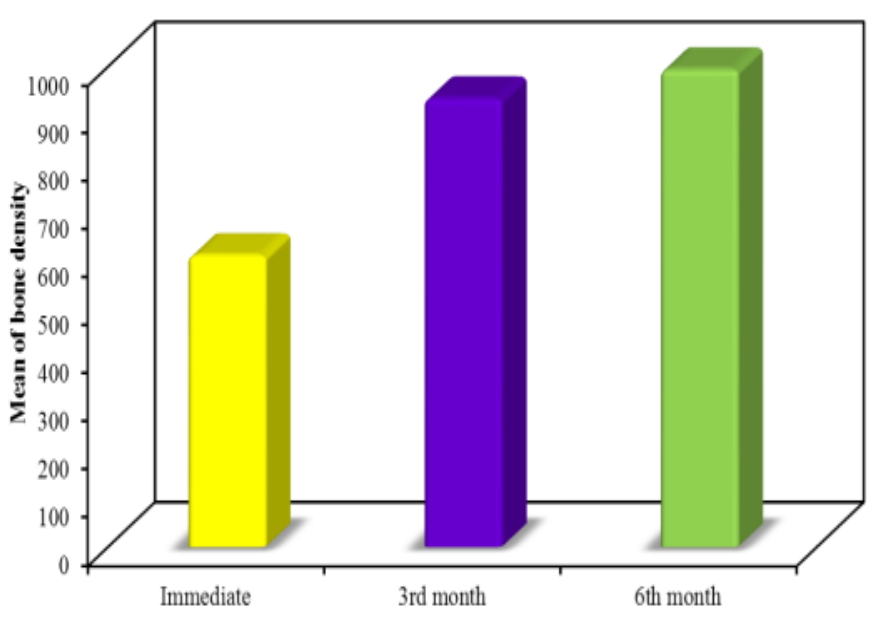

Figure 4: Comparison between the three periods according to bone density. 
Table (3): Comparison between the three periods according to MBL

\begin{tabular}{||l|c|c|c|c|c||}
\hline \multicolumn{1}{|c|}{ MBL } & $\begin{array}{c}\text { Immedia } \\
\text { te }\end{array}$ & $\begin{array}{c}3^{\text {rd }} \\
\text { month }\end{array}$ & $\mathbf{6}^{\text {th }}$ month & F & p \\
\hline Min. - Max. & $0.16-0.68$ & $0.36-0.85$ & $0.56-1.06$ & & \\
Mean \pm SD. & $0.40 \pm 0.13$ & $0.63 \pm 0.13$ & $0.80 \pm 0.14$ & $122.589^{*}$ & $<0.001^{*}$ \\
Median & 0.38 & 0.62 & 0.78 & & \\
\hline Sig. bet. periods & \multicolumn{2}{|c|}{$\mathrm{p}_{1}<0.001^{*}, \mathrm{p}_{2}<0.001^{*}, \mathrm{p}_{3}<0.001^{*}$} & & \\
\hline
\end{tabular}

F: F test (ANOVA) with repeated measures, Pairwise comparison bet. each 2 groups was done using Post Hoc Test (Bonferroni)

p: $\mathrm{p}$ values for comparing between three periods

p1: p values for comparing between Immediate and $3^{\text {rd }}$ month

p2: p values for comparing between Immediate and $\mathbf{6}^{\text {th }}$ month

$\mathbf{p}_{3}$ : $\mathrm{p}$ values for comparing between $3^{\text {rd }}$ month and $6^{\text {th }}$ month

*: Statistically significant at $\mathrm{p} \leq 0.05$

t: Paired t-test

p: p values for comparing between two periods

*: Statistically significant at $\mathrm{p} \leq 0.05$

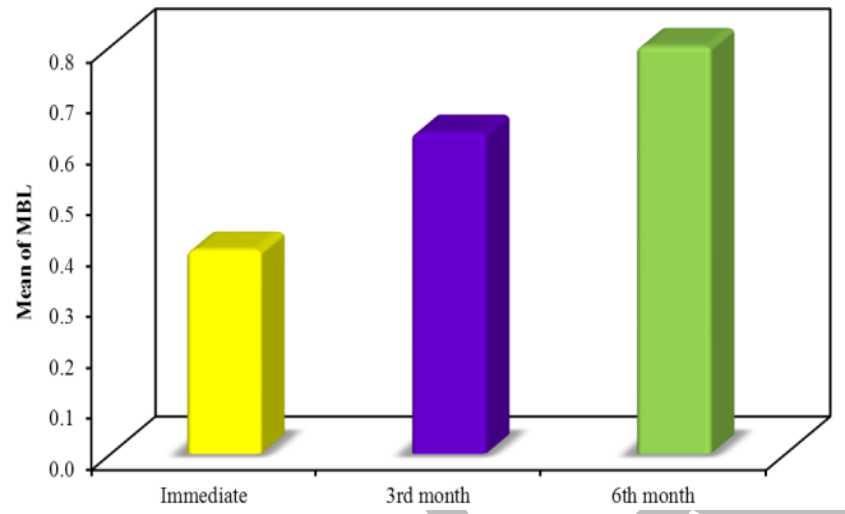

Figure 5: Comparison between the three periods according to MBL.

\section{DISCUSSION}

This present study was conducted on thirteen patients in need for implant placement for their lost mandibular posterior teeth with adequate bone quality and inter-occlusal space. They were selected from the Outpatient Clinic of the Oral and Maxillofacial Surgery Department, Faculty of Dentistry, Alexandria University.

Patients suffering from bruxism, heavy smokers, patients receiving chemotherapy or radiotherapy and immunosupressed patients were excluded from this study. This was according to a study performed by Gomez de Diego et al in 2014 (15).

As regards the surgical procedure, all implants were inserted according to the manufacturer's recommendations, and the drilling was performed under profuse irrigation using normal saline for proper cooling and to avoid overheating of the bone tissues which would compromise osseointegration in accordance to Strbac et al., in 2014 (16). This also matches findings obtained by Lee et al., in 2012 (17) and Augustin et al., in 2012 (18).

As regards the surgical procedures, all included patients were subjected to delicate and a traumatic surgery using single drilling osteotomy.

This technique offers significant advantages to both the patient and the clinician. Less time is needed for surgical procedures and surgical site exposure, avoidance of excessive temperature generation, mechanical damage and high frictional forces during surgical drilling.

According to Penarrocha M et al. in 2006 (19), Jimbo R et al. in 2014 (20) and Giro G et al. in 2013 (21), Prolonged tissue exposure is also known to have a negative effect on postoperative course due to the increased release of proinflammatory cytokines and amplified inflammatory response. In order to achieve less hands-on time in dental implant surgery and to improve accuracy, a simplified drilling protocol was pursued. Therefore, a protocol with guided support, achieving less micro movement, was set up. Previous studies have reported that simplifications of the traditional gradual expansion result in bone apposition to implants that is comparable with traditional techniques.

Several publications suggested that, reducing the number of drill steps is not compromising clinical results (22-24). Limiting the duration of surgical intervention to better healing and more patient satisfaction (25).

According to Nadine Marheineke et al. in 2018 (26), higher accuracy of implant preparations were generated by single step drill protocols, which might result in an increased primary stability. Also, a reduction of the number of drilling steps leads to a reduction of potential sources of errors. This also matches findings obtained by Jung RE et al. 2008 (27) and Schneider et al. in 2009 (28).

In the present study, the implant stability was measured using the Resonance Frequency Analysis (RFA) via the Osstell ISQ system immediately, 3 and 6 months postoperative. RFA was chosen as a non-invasive and reliable method to assess variation in implant stability over time. RFA registrations are directly related to the stiffness of the implant in the surrounding bone: during healing an increase in implant stability quotient (ISQ) values presumably reflect new bone apposition at the implant-bone interface (29).

Primary stability of implants is known to be dependent on several factors: material, surface, diameter, and shape of the dental implant itself as well as practical factors during the surgery (30-32). Correct use and insertion of the dental implant are obligatory for successful surgery. The precise site preparation of the drilling hole and choice of corresponding drilling tools and implant systems is very essential as well $(33,34)$.

Regarding the presence of pain, Pain was evaluated daily for two weeks using visual analogue scale (VAS) from 0 to 10 ("0" is pain free and "10" is unbearable pain). After surgery, five patients experienced mild pain (VAS=2-4), three patients experienced moderate pain (VAS=5-7), one patient experienced severe pain and four patients experienced no pain at surgical site for 1-3 days duration. During the follow up period, all patients felt no pain after implant placement except one case that felt severe postoperative pain in the first week after implant placement.

These results are in accordance with the studies performed by Hashem et al., in 2006 (35) and Karabuda et al., in 2007 
(36) they stated that pain following implant placement ranged from mild to moderate on VAS. In both studies, the peak of pain perception occurred on day one following surgery.

From the clinical evaluation, which was extended up to 2 weeks, regarding the presence of swelling, only one implant displayed swelling in the operated area after one week and needed removal (failure case). Early swelling around the implant and failure of this case could be attributed to lack of oral hygiene maintenance by the patient and so infection occurred in spite of the instructions given to her. This was compatible with Al-Sabbagh M and Bhavsar I in 2015 (37) who stated that the clinical signs of peri-implant infection are considered to be associated with implant failures.

In this study, the mean bone density increased significantly towards the six month post-operatively. This can attribute to the healing of the bone around implants. These results were in agreement with the results of Al-Sudani RJ in 2014 (38) who studied twenty implants in the premolar and molar region of both maxilla and mandible by using CBCT evaluation to measure the bone density by using $\mathrm{HU}$ around dental implants. The mean $\mathrm{HU}$ of jaw bone immediately following implant placement was 552.28 HU and increased significantly to $761.33 \mathrm{HU}$ after six months.

Regarding peri-implant bone level, there was statistically significant difference in the mean of peri-implant bone level changes toward the sixth month. This was matched to the study that was done by Jung RE 2012 (39) and Galindo Moreno et al 2015 (40), who stated that despite the excellent survival rates of dental implants, long term studies have shown 1.5 to $2 \mathrm{~mm}$ of bone loss around the neck of the implant during the first year of functional loading and an annual rate of marginal bone loss (MBL) around $0.2 \mathrm{~mm}$, after the first year.

\section{CONCLUSIONS}

Within the limits of this study, the overall conclusion that can be drawn from this study is that single drilling osteotomy technique has been a highly successful, predictable procedure. It facilitates implant insertion with satisfactory clinical outcomes and low incidence of complications.

\section{CONFLICT OF INTERSET}

The authors declare that they have no conflicts of interest.

\section{REFERENCES}

1. Adell R, Lekholm U, Rockler B, Branmark OI. A 15year study of osseointegarted implants in the treatment of the edentulous jaw. Int J Oral Surg. 1981; 10:387-416.

2. Albrektsson T. direct bone anchorage of dental implant. J Prosthet Dent. 1983; 50:255-61.

3. O'Sullivan D, Sennerby L, Jagger D, Meredith N. Comparison of two methods of enhancing implant primary stability. Clin Implant Dent Relat Res. 2004; 6:48-57.

4. Davidson SR, James DF. Drilling in bone: modelling heat generation and temperature distribution. J Biomech Eng. 2003; 125:305-14.
5. Augustin G, Davila S, Mihoci K, Udiljak T, Vedrina DV, Antabak A. Thermal osteonecrosis and bone drilling parameters revisited. Arch Orthop Trauma Surg. 2008; 128:71-7.

6. Scarano A, Piattelli A, Assenza B, Carinci F, Di Donato L, Romani GL, et al. Infrared thermographic evaluation of temperature modifications induced during implant site preparation with cylindrical versus conical drills. Clin Implant Dent Relat Res. 2011; 13:319-23.

7. Flanagan D. Osteotomy irrigation: is it necessary? Implant Dent. 2010; 19:241-9.

8. Brisman DL. The effect of speed, pressure, and time on bone temperature during the drilling of implant sites. Int J Oral Maxillofac Implants. 1996;11:35-7.

9. Chacon GE, Bower DL, Larsen PE, McGlumphy EA, Beck FM. Heat production by 3 implant drill systems after repeated drilling and sterilization. J Oral Maxillofac Surg 2006; 64: 265-9.

10. Bubeck KA, García-López J, Maranda LS. In vitro comparison of cortical bone temperature generation between traditional sequential drilling and a newly designed step drill in the equine third metacarpal bone. Vet Comp Orthop Traumatol 2009; 22: 442-7.

11. Albrektsson T, Branemark PI, Hansson HA, Lindstrem J. Osseointegrated titanium implants. Requirements for ensuring a long-lasting, direct bone-to-implant anchorage in man. Acta Orthop Scand. 1981; 52:155-70.

12. IBS implant, Dream Series, H-1 drill - Suppliers of dental implant, fixture from South Korea. IBS Implant. 2010. Available at: http://ibsimplant.blogspot.com.eg/

13. Le Resche L, Burgess J, Dworkin SF. Reliability of visual analoge and verbal descriptor scales for "objective" measurement of tempromandibular disorder pain. J Dent Res 2000; 67: 33-6.

14. Kirkpatrick LA, Feeney BC. A simple guide to IBM SPSS statistics for version 20.0. Student ed. Belmont, Calif.: Wadsworth, Cengage Learning; 2013.

15. Gomez-de Diego R, Mang-de la Rosa Mdel R, RomeroPerez MJ, Cutando-Soriano A, Lopez-Valverde-Centeno A. Indications and contraindications of dental implants in medically compromised patients: update. Med Oral Patol Oral Cir Bucal. 2014; 19:e483-9.

16. Strbac GD, Unger E, Donner R, Bijak M, Watzek G, Zechner W. Thermal effects of a combined irrigation method during implant site drilling. A standardized in vitro study using a bovine rib model. Clin Oral Implants Res. 2014; 25:665-74.

17.Lee J, Ozdoganlar OB, Rabin Y. An experimental investigation on thermal exposure during bone drilling. Med Eng Phys. 2012; 34:1510-20.

18.Augustin G, Davila S, Udillijak T, Staroveski T, Brezak $\mathrm{D}$, Babic S. Temperature changes during cortical bone drilling with a newly designed step drill and an internally cooled drill. Int Orthop. 2012; 36:1449-56.

19.Penarrocha M, Garcia B, Marti E, Balaguer J. Pain and inflammation after periapical surgery in 60 patients. J Oral Maxillofac Surg. 2006; 64:429-33.

20.Jimbo R, Janal MN, Marin C, Giro G, Tovar N, Coelho PG. The effect of implant diameter on osseointegration utilizing simplified drilling protocols. Clin Oral Implants Res. 2014; 25:1295-300. 
21.Giro G, Tovar N, Marin C, Bonfante EA, Jimbo R, Suzuki M, et al. The effect of simplifying dental implant drilling sequence on osseointegration: an experimental study in dogs. Int J Biomater 2013; 2013:230310.

22. Bettach R, Taschieri S, Boukhris G, Del Fabbro M. Implant survival after preparation of the implant site using a single bur: a case series. Clin Implant Dent Relat Res. 2015;17:13-21.

23.Gehrke SA. Evaluation of the Cortical Bone Reaction Around of Implants Using a Single-Use Final Drill: A Histologic Study. J Craniofac Surg 2015; 26:1482-6.

24. Gehrke SA, Bettach R, Taschieri S, Boukhris G, Corbella S, Del Fabbro M. Temperature Changes in Cortical Bone after Implant Site Preparation Using a Single Bur versus Multiple Drilling Steps: An In Vitro Investigation. Clin Implant Dent Relat Res 2015;17:700-7.

25.Bratu E, Mihali S, Shapira L, Bratu DC, Wang HL. Crestal bone remodeling around implants placed using a short drilling protocol. Int J Oral Maxillofac Implants. 2015; 30:435-40.

26. Marheineke N, Scherer U, Rucker M, von See C, Rahlf B, Gellrich NC, et al. Evaluation of accuracy in implant site preparation performed in single- or multi-step drilling procedures. Clin Oral Investig. 2018; 22:2057-67.

27.Jung RE, Pjetursson BE, Glauser R, Zembic A, Zwahlen M, Lang NP. A systematic review of the 5-year survival and complication rates of implant-supported single crowns. Clin Oral Implants Res. 2008; 19:119-30.

28.Schneider D, Marquardt P, Zwahlen M, Jung RE. A systematic review on the accuracy and the clinical outcome of computer-guided template-based implant dentistry. Clin Oral Implants Res. 2009; 20:73-86.

29.Sim CP, Lang NP. Factors influencing resonance frequency analysis assessed by Osstell mentor during implant tissue integration: I. Instrument positioning, bone structure, implant length. Clin Oral Implants Res. 2010; 21:598-604.

30.Sennerby L, Meredith N. Implant stability measurements using resonance frequency analysis: biological and biomechanical aspects and clinical implications. Periodontol 2000 2008;47:51-66.
31. Kim SK, Lee HN, Choi YC, Heo SJ, Lee CW, Choie MK. Effects of anodized oxidation or turned implants on bone healing after using conventional drilling or trabecular compaction technique: histomorphometric analysis and RFA. Clin Oral Implants Res. 2006; 17:644-50.

32.Friberg B, Ekestubbe A, Sennerby L. Clinical outcome of Branemark System implants of various diameters: a retrospective study. Int J Oral Maxillofac Implants. 2002; 17:671-7.

33.Scherer U, Stoetzer M, Ruecker M, Gellrich NC, von See C. Template-guided vs. non-guided drilling in site preparation of dental implants. Clin Oral Investig. 2015; 19:1339-46.

34.Tabassum A, Meijer GJ, Wolke JG, Jansen JA. Influence of surgical technique and surface roughness on the primary stability of an implant in artificial bone with different cortical thickness: a laboratory study. Clin Oral Implants Res. 2010; 21:213-20.

35.Hashem AA, Claffey NM, O'Connell B. Pain and anxiety following the placement of dental implants. Int $\mathrm{J}$ Oral Maxillofac Implants. 2006; 21:943-50.

36.Karabuda ZC, Bolukbasi N, Aral A, Basegmez-Zeren C, Ozdemir $\mathrm{T}$. Comparison of analgesic and antiinflammatory efficacy of selective and non-selective cyclooxygenase-2 inhibitors in dental implant surgery. J Periodontol. 2007; 78:2284-8.

37.Al-Sabbagh M, Bhavsar I. Key local and surgical factors related to implant failure. Dent Clin North Am. 2015; 59:1-23.

38.Al-Sudani RJ. Assessment of bone density after six months from dental implants placement using Computed Tomography. J Baghdad Coll Dent. 2014; 26:126-8.

39.Jung RE, Zembic A, Pjetursson BE, Zwahlen M, Thoma DS. Systematic review of the survival rate and the incidence of biological, technical, and aesthetic complications of single crowns on implants reported in longitudinal studies with a mean follow-up of 5 years. Clin Oral Implants Res. 2012; 23:2-21.

40.Galindo-Moreno P, Leon-Cano A, Ortega-Oller I, Monje A, F OV, Catena A. Marginal bone loss as success criterion in implant dentistry: beyond $2 \mathrm{~mm}$. Clin Oral Implants Res. 2015;26:28-34. 